Communication

\title{
Improvement of the EC Performance in LCP-MOF Electrode Materials by Succinic Anhydrate Addition to the Electrolyte
}

\author{
Mohamed Gaber Moustafa ${ }^{1,2, *}$, Abdelaziz Mohamed Aboraia ${ }^{3,4} *\left(\mathbb{D}\right.$, Vera Butova ${ }^{3}$, Alexander Guda ${ }^{3}$ (D), \\ Fatma Elmasry ${ }^{5,6}$ and Alexander Soldatov ${ }^{3}$
}

check for

updates

Citation: Moustafa, M.G.; Aboraia,

A.M.; Butova, V.; Guda, A.; Elmasry,

F.; Soldatov, A. Improvement of the EC Performance in LCP-MOF Electrode Materials by Succinic Anhydrate Addition to the Electrolyte. Sustainability 2022, 14, 323. https://doi.org/10.3390/ su14010323

Academic Editors: Marc A. Rosen and Thanikanti Sudhakar Babu

Received: 26 September 2021 Accepted: 22 December 2021 Published: 29 December 2021

Publisher's Note: MDPI stays neutral with regard to jurisdictional claims in published maps and institutional affiliations.

Copyright: (C) 2021 by the authors. Licensee MDPI, Basel, Switzerland. This article is an open access article distributed under the terms and conditions of the Creative Commons Attribution (CC BY) license (https:// creativecommons.org/licenses/by/ $4.0 /)$.
1 Physics Department, College of Science and Arts, Jouf University, Qurayat 75911, Saudi Arabia 2 Physics Department, Faculty of Science, Al-Azhar University, Cairo 11884, Egypt

3 The Smart Materials Research Institute, Southern Federal University, Sladkova 178/24, 344090 Rostov-on-Don, Russia; butovav86@gmail.com (V.B.); guda_sasha@mail.ru (A.G.); soldatov@sfedu.ru (A.S.)

4 Physics Department, Faculty of Science, Al-Azhar University, Assiut 71542, Egypt

5 Physics Department, College of Science and Arts, Jouf University, Tabrjal 74713, Saudi Arabia; elmasryfatma1440@gmail.com

6 Department of Physics, Faculty of Science, Suez Canal University, Ismailia 41522, Egypt

* Correspondence: mgmoustafa@azhar.edu.eg (M.G.M.); a.m.aboraia@gmail.com (A.M.A.)

\begin{abstract}
The optimization of the electrolyte composition for a canonical cathode such as $\mathrm{LiCoPO}_{4}$ olivine. The implemented succinic anhydride within a liquid electrolyte $\mathrm{LiPF}_{6}$ and dissolved in carbonate/diethyl considerably improves the discharge capacity of the electrode are shown. The introduction of succinic anhydride into the solid/electrolyte interphase (SEI) layer is responsible for the improved electrochemical performance of the electrode. We used $\mathrm{LiCoPO}_{4} @ \mathrm{C}-\mathrm{ZrO}_{2}$ as a cathode to prove the concept. The observed results could be applied for a wide range of cathodes. Moreover, the proposed additive to the electrolyte could help evaluate the performance of the materials without the side effects of the electrolyte.
\end{abstract}

Keywords: $\mathrm{LiPF}_{6}$; succinic anhydride; energy storage and conversion; nanocomposite; XRD

\section{Introduction}

One of the most promising olivine structures is $\mathrm{LiCoPO}_{4}(\mathrm{LCP})$ as a cathode material due to its high redox potential of around $4.8 \mathrm{~V}$, its high energy density, and its theoretical capacity of $\sim 167 \mathrm{mAhg}^{-1}$ [1-3]. Nevertheless, it undergoes a low electrochemical performance for many reasons, such as its low lithium-ion and electronic conductivity and its high voltage effect on the lifetime of the electrolyte (stability) [4,5]. Several works have used $\mathrm{LiPF}_{6}$ as a standard electrolyte. However, it suffers from a low thermostability and a fast capacity fading because of the oxidation of the organic carbonate solvents at high voltages, and the decomposition of $\mathrm{LiPF}_{6}[6,7]$. Regrettably, this degradation affects the electrochemical performance. In particular, once the working potential exceeds $4.4 \mathrm{~V}$, it initiates a continuous reduction of the electrolyte due to an oxidative carbonate decomposition. Furthermore, the $\mathrm{LiPF}_{6}$ converts to $\mathrm{PF}_{5}$ and $\mathrm{LiF}$ under high voltage; thus, the cobalt is dissolved from and causes the structural collapse of the LCP, which is the result of undergoing from HF attack. Here, we report the protective effect of various amounts of succinic anhydride additive on $\mathrm{LiPF}_{6}$ electrolyte properties.

\section{Experimental Work \\ UiO-66 Preparation}

To synthesize UiO-66, we used the same technique from Ref. [4]. The $\mathrm{ZrCl}_{4}$ was dispersed in a DMF, then deionized water and benzoic acid (BA) were added and totally dissolved. The terephthalic acid $\left(\mathrm{H}_{2} \mathrm{BDC}\right)$ linker was poured into a solution with a molar 
ratio $\mathrm{Zr}: \mathrm{BDC}: \mathrm{BA}: \mathrm{H}_{2} \mathrm{O}: \mathrm{DMF}$ that was 1:1:10:3:300. The net solution was placed into a capped vessel in the oven for $24 \mathrm{~h}$ at $120^{\circ} \mathrm{C}$. When the temperature was cooled to room temperature, the white precipitate was washed with DMF once as well as methanol, and washed overnight at $100{ }^{\circ} \mathrm{C}$. The size of the particle was $\sim 100 \mathrm{~nm}$ and the area of the surface was $1500 \mathrm{~m}^{2} \mathrm{~g}^{-1}$. The XRD confirmed that UiO-66 has a single phase, as shown in Figure S1.

\section{LiCoPO4/C Coated by UiO-66 MOF Composite Preparation}

The active material was prepared by a one-time facile method in three hours, as published elsewhere [4]. We used two solutions, A and B; since solution A consists of LiOH. $\mathrm{H}_{2} \mathrm{O}(0.0735 \mathrm{~g})$, it was dispersed in $333 \mu \mathrm{L}$ of deionized (DI) water plus ethylene glycol $(6.67 \mathrm{~mL})$. In solution $\mathrm{B}$, we mixed $\mathrm{LiOH} . \mathrm{H}_{2} \mathrm{O}(0.0420 \mathrm{~g})$ with $1 \mathrm{~mL}$ DI water, $\mathrm{H}_{3} \mathrm{PO}_{4}$ $(68.3 \mu \mathrm{L}), 132 \mathrm{~mL}$ DI water, $0.2910 \mathrm{~g}$ of $\mathrm{Co}\left(\mathrm{NO}_{3}\right)_{2} \cdot 6 \mathrm{H}_{2} \mathrm{O}, 1026 \times 10^{-4} \mathrm{~g}$ of $\mathrm{C}_{6} \mathrm{H}_{12} \mathrm{O}_{6}$, and $145 \times 10^{-3} \mathrm{~g}$ of the UiO-66, then it was mixed by a magnetic stirrer. In the end, we mixed solutions A and B into a Teflon vessel at $220^{\circ} \mathrm{C}$ in a microwave (MARS) for three hours under $800 \mathrm{~W}$. The final precipitate (blue color) was separated via centrifuging and washed once with water and three times with ethanol. The final product was activated under air for seven hours at $650{ }^{\circ} \mathrm{C}$.

\subsection{X-ray Characterization}

The as-prepared sample was examined by the X-ray diffractometer D2 Phaser (Bruker, Germany) using $\mathrm{Cu} \mathrm{K} \alpha_{1}$ radiation $(\lambda=1.540598 \AA)$. The element analysis of the asprepared samples was carried out by utilizing the Bruker M4-Tornado X-ray fluorescence spectrometer.

\subsection{TEM Photos}

The microstructures of the as-prepared samples were examined by the FEI Tecnai G2 Spirit TWIN transmission electron microscope, operated at an accelerating voltage of $80 \mathrm{kV}$.

\subsection{Electrochemical Characterization}

The electrochemical performance of $\mathrm{LiCoPO}_{4} @ \mathrm{UiO}-66$ was examined by galvanostatic lithiation/delithiation utilizing a P-20X potentiostat/galvanostat device (Elins, Russia). The active material $\left(7.5 \mathrm{mg} \mathrm{cm}^{-2}\right.$ load of active material) was mixed with carbon black $80 \%$ and $20 \%$, respectively. The mixture was located in the cell as a half-cell of the cathode materials and the anode was lithium foil. The used separator was a glass microfiber filter and $1 \mathrm{M} \mathrm{LiPF}_{6}$ in $\mathrm{EC} / \mathrm{DMC}=50 / 50(v / v)$ (Sigma-Aldrich) as an electrolyte, with different ratios of succinic anhydride as an additive (0 wt.\%, $2 \mathrm{wt} . \%, 3 \mathrm{wt} . \%)$. The cell was collected under Ar in a glove bag purchased from Sigma-Aldrich, and the cycling was performed in 3-5.1 V with current C/10.

\subsection{Result and Discussion}

The sample was identified by X-ray diffraction. Figure 1 demonstrates the PXRD of $\mathrm{LiCoPO}_{4} / \mathrm{c} @ U i \mathrm{U}-66$ nanoparticles, which were synthesized by the microwave-assisted

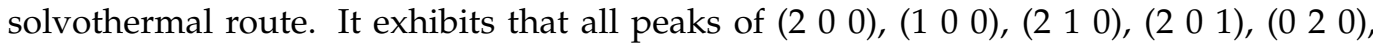
(3 0 1), (1 2 1 $),\left(\begin{array}{lll}4 & 0 & 1\end{array}\right)$, and (2 3 1) planes were matched with Cod: 2300246. This result proved that the LCP/C@UiO-66 has a single orthorhombic phase with a Pnma space group without any additional peaks corresponding to other phases, and lattice parameters as follows: $a=10.2 \AA, b=5.9 \AA$, and $c=4.7 \AA$, as shown in Figure 1. A small amount of UiO-66 coated the $\mathrm{LiCoPO}_{4}$, thus the UiO-66 formed on the surface and did not appear in the XRD. The TEM photos confirmed the presence of some tiny crystals of $\mathrm{ZrO}_{2}$ on the surface of $\mathrm{LiCoPO}_{4}$, since the average size of $\mathrm{LiCoPO}_{4}$ is $100 \mathrm{~nm}$, but the $\mathrm{ZrO}_{2}$ is around $9 \mathrm{~nm}$, as exhibited in Figure 2a,b. To identify the type of the small particles, we used X-ray fluorescence spectroscopy, which confirmed a small concentration of $\mathrm{Zr}$ at around 3.7\% and $67 \%$ of cobalt. 


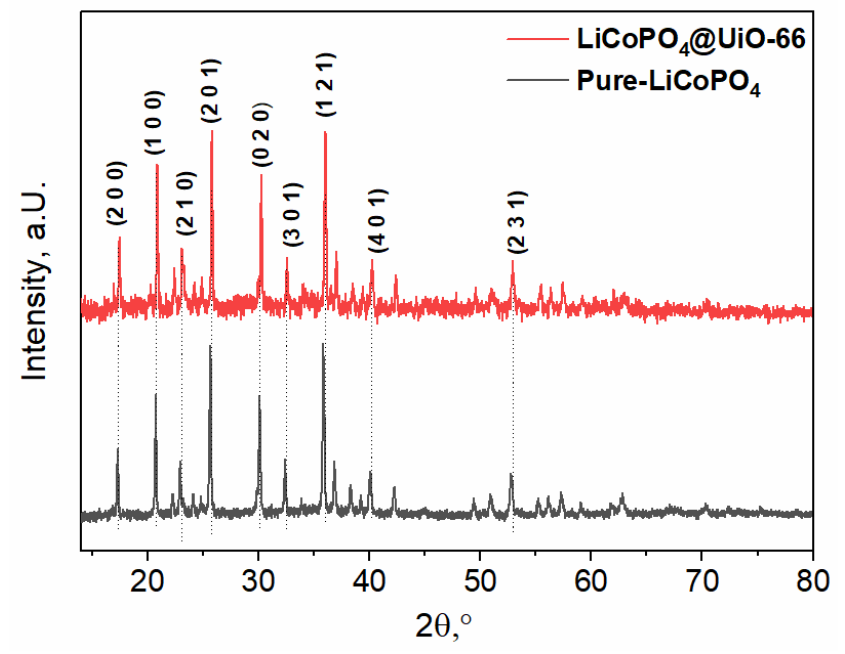

Figure 1. PXRD of pure $\mathrm{LiCoPO}_{4}$ and $\mathrm{LiCoPO}_{4}$ coated by $\mathrm{UiO}-66$.
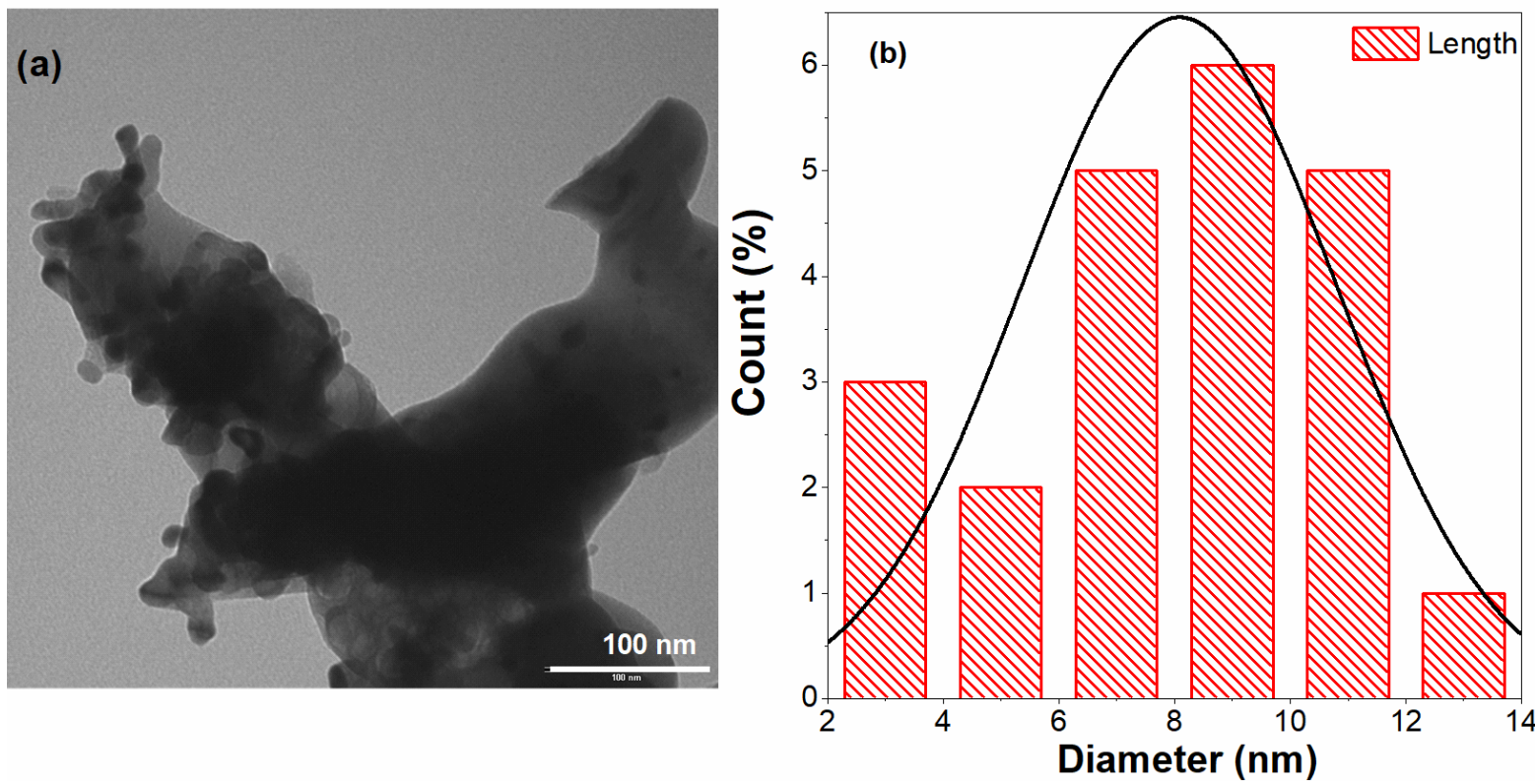

Figure 2. (a) TEM photo of $\mathrm{LiCoPO}_{4} @ \mathrm{UiO}-66$. (b) The histogram of the small nano $\mathrm{ZrO}_{2}$ particle distribution.

The cell was assembled under Ar by using the conventional liquid electrolyte $\mathrm{LiPF}_{6}$. The charge/discharge process of the LCP was carried out at C/10 in the voltage range 2.75-5.1 V. The result displayed that the initial discharge capacity of LCP without additives is around $\sim 105 \mathrm{mAh} . \mathrm{g}^{-1}$. An increase in the concentration of additives enhances the electrochemical performance, as shown in Figure 3a. Since the discharge capacity with $2 \%$ of succinic anhydrate is around $120 \mathrm{mAh} / \mathrm{g}$, a synergistic $3 \%$ of succinic anhydrate improved the first discharge capacity up to $147 \mathrm{mAh} / \mathrm{g}$. Furthermore, from the first to the fourth cycles, a good enhancement in the electrochemical performance appears, as demonstrated in Figure 3b. Meanwhile, inserting a concentration of succinic anhydride of more than 3\% stopped the electrochemical performance of the cell; therefore, we preferred the 3\%, as seen in Figure S2. 

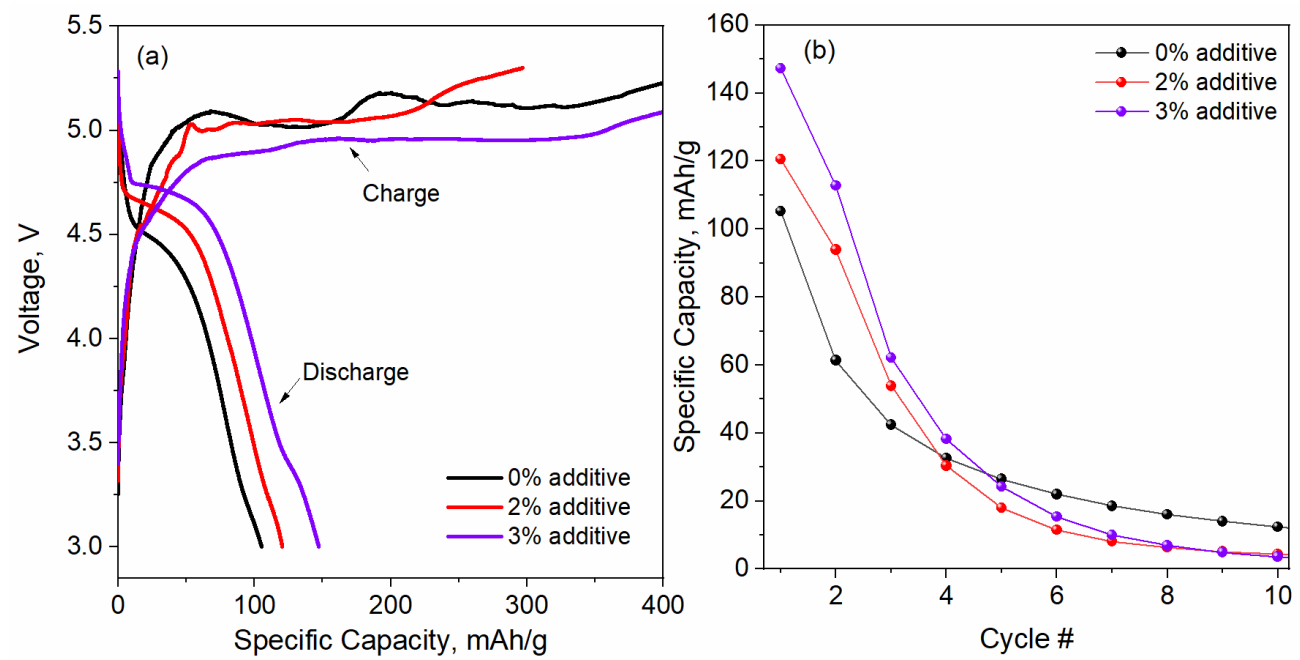

Figure 3. (a) Comparison of the initial cycles of $\mathrm{LiCoPO}_{4} / \mathrm{C} @ U i O-66$ with different concentrations of additives (succinic). (b) Comparison of the ten cycles of $\mathrm{LiCoPO}_{4} / \mathrm{C} @ \mathrm{UiO}-66$ with varying concentrations of additives.

Figure 4a-c show the comparisons of the electrochemical performance of $\mathrm{LiCoPO}_{4} /$ C@UiO-66 with different concentrations of additives (succinic, 0\%, 2\%, and 3\%). The enhancement in the electrochemical performance is apparent, and the discharge capacity of the sample without any additives was $105 \mathrm{mAh} / \mathrm{g}$ for the first cycle, as shown in Figure 4a. However, inserting $2 \%$ of the succinic led to an enhancement of the discharge capacity to $121 \mathrm{mAh} / \mathrm{g}$, and $3 \%$ improved the discharge capacity to $147 \mathrm{mAh} / \mathrm{g}$. Meanwhile, the concentration was limited to 3\% because inserting more than 3\% (such as $4 \%$ and $7 \%$ ) stopped the discharge and the cycle was not completed; thus, the best concentration of succinic is 3\%. The second cycle of $\mathrm{LiCoPO}_{4} / \mathrm{C} @ \mathrm{UiO}-66$ with different concentrations of additives (succinic, $0 \%, 2 \%$, and $3 \%$ ) was improved from 60 to $119 \mathrm{mAh} / \mathrm{g}$, as demonstrated in Figure $4 \mathrm{a}-\mathrm{c}$. We note that the fade in the discharge capacity of all the samples was improved, according to Figure $4 \mathrm{a}-\mathrm{c}$. An introduction of a small amount (3 wt.\%) of succinic anhydrate into the liquid electrolyte could improve the electrochemical performance of the $\mathrm{LiCoPO}_{4} @ \mathrm{UiO}-66$ electrode during cycling without sacrificing the charge-discharge potential. This enhancement in the electrochemical performance of a $\mathrm{LiCoPO}_{4} @ \mathrm{UiO}-66$ electrode is found to be due to the modification of the SEI layer on the LCP surface with the introduction of the succinic anhydrate additive. The presence of succinic anhydrate can prevent the decomposition of the LiPF6 salt on the LCP surface.

To better understand what occurred for the active materials during the charge and discharge process, we measured the ex situ XAS for the $\mathrm{LiCoPO}_{4}$ coated by the UiO-66. The $\mathrm{Co}$ (II) is almost transformed to $\mathrm{Co}(\mathrm{III})$, thus nearly all of the lithium ions were extracted completely, as shown in Figure 5. We observed a two-step system in the first charge process, which implies the development of the intermediate $\mathrm{Li} 0.7 \mathrm{CoPO} 4$ phase, as observed by Bramnik et al. [8]. 


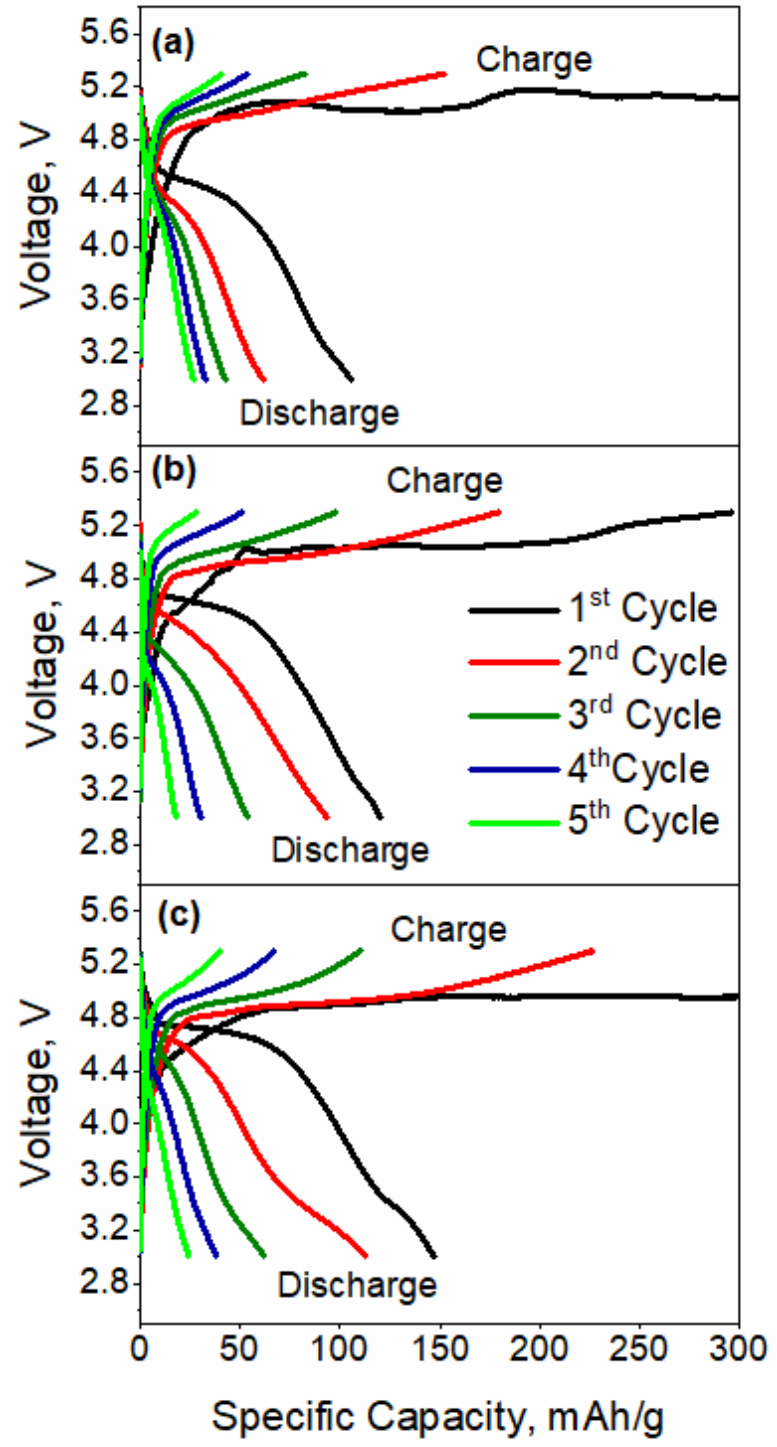

Figure 4. First five cycles of (a) $\mathrm{LiCoPO}_{4}$ without additives, (b) $\mathrm{LiCoPO}_{4}$ with $2 \%$ additives, and (c) $\mathrm{LiCoPO}_{4}$ with $2 \%$ additives.

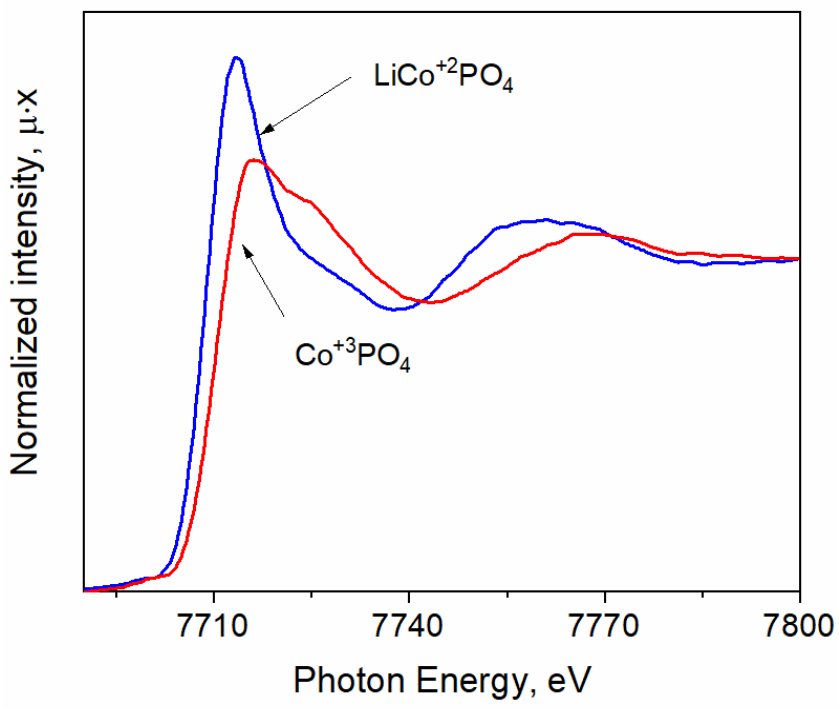

Figure 5. The XAS for first cycle and last spectra of first discharge. 


\section{Conclusions}

The $\mathrm{LiCoPO}_{4}$ coated by UiO-66 was prepared by a microwave-assisted solvothermal route. The XRD proved that the $\mathrm{LiCoPO}_{4}$ coated by UiO-66 is a single-phase without any crystal impurities. The TEM images ensure that there are some nanoparticles of $\mathrm{ZrO}_{2}$ on the surface of $\mathrm{LiCoPO}_{4}$. The electrochemical performance of $\mathrm{LiCoPO}_{4}$ is low due to the performance of the $\mathrm{LiPF}_{6}$; thus, the incorporated succinic as an additive in the $\mathrm{LiPF}_{6}$ electrolyte led to the enhancement of the electrochemical performance of $\mathrm{LiCoPO}_{4} / \mathrm{C}$ coated by UiO-66 and a discharge capacity from 105 to $147 \mathrm{mAh} / \mathrm{g}$. The best concentration of the succinic anhydrate additive was $3 \%$ in the $\mathrm{LiPF}_{6}$ electrolyte. Meanwhile, concentrations of more than $3 \%$ had side effects on the electrochemical performance. We observed a two-step system in the first charge process, which implies the development of the intermediate $\mathrm{Li} 0.7 \mathrm{CoPO} 4$ phase.

Supplementary Materials: The following supporting information can be downloaded at: https: / / www.mdpi.com/article/10.3390/su14010323/s1, Figure S1: 1(a) Experimental (red) and calculated (black) profiles of the synthesized sample UiO-66. Vertical lines indicate calculated pick positions. A difference plot (blue) isprovided at the bottom. Figure S2: the electrochemical performance of $\mathrm{LiCoPO}_{4} @ \mathrm{UiO}-66$ with $4 \%$ addative.

Author Contributions: Conceptualization, A.M.A. and V.B.; methodology, A.M.A.; software, M.G.M.; validation, A.M.A., V.B. and A.G.; formal analysis, M.G.M.; investigation, F.E.; resources, M.G.M.; data curation, A.M.A.; writing-original draft preparation, A.M.A. and V.B.; writing-review and editing, M.G.M. and A.G.; visualization, A.M.A. and F.E.; su-pervision, A.S.; project administration, M.G.M.; funding acquisition, M.G.M. All authors have read and agreed to the published version of the manuscript.

Funding: Deputyship for Research and Innovation, Ministry of Education, Saudi Arabia, for funding this work through the project number "1470020316".

Institutional Review Board Statement: Not applicable.

Informed Consent Statement: Not applicable.

Data Availability Statement: Not applicable.

Acknowledgments: The authors extend their appreciation to the Deputyship for Research and Innovation, Ministry of Education, Saudi Arabia, for funding this work through the project number "1470020316". The authors would like to extend their sincere appreciation to the central laboratory at Jouf University for their support in this study.

Conflicts of Interest: The authors declare no conflict of interest.

\section{References}

1. Wu, X.; Meledina, M.; Tempel, H.; Kungl, H.; Mayer, J.; Eichel, R.-A. Morphology-controllable synthesis of LiCoPO 4 and its influence on electrochemical performance for high-voltage lithium ion batteries. J. Power Sources 2020, 450, 227726. [CrossRef]

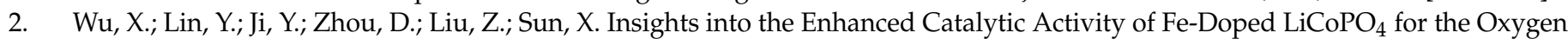
Evolution Reaction. ACS Appl. Energy Mater. 2020, 3, 2959-2965. [CrossRef]

3. Gnewuch, S.; Rodriguez, E.E. Distinguishing the Intrinsic Antiferromagnetism in Polycrystalline $\mathrm{LiCoPO}_{4}$ and $\mathrm{LiMnPO}_{4} \mathrm{Olivines}_{\text {. }}$ Inorg. Chem. 2020, 59, 5883-5895. [CrossRef] [PubMed]

4. Aboraia, A.M.; Shapovalov, V.V.; Guda, A.A.; Butova, V.V.; Soldatov, A. One-pot coating of $\mathrm{LiCoPO}_{4} / \mathrm{C}$ by a UiO-66 metal-organic framework. RSC Adv. 2020, 10, 35206-35213. [CrossRef]

5. Aboraia, A.M.; Shapovalov, V.V.; Guda, A.A.; Butova, V.V.; Zahran, H.Y.; Yahia, I.S.; Soldatov, A.V. Activation of LiCoPO 4 in Air. J. Electron. Mater. 2021, 50, 3105-3110. [CrossRef]

6. Han, J.-G.; Jeong, M.-Y.; Kim, K.; Park, C.; Sung, C.H.; Bak, D.W.; Kim, K.H.; Jeong, K.-M.; Choi, N.-S. An electrolyte additive capable of scavenging HF and PF5 enables fast charging of lithium-ion batteries in LiPF6-based electrolytes. J. Power Sources 2020, 446, 227366. [CrossRef]

7. Tarnopolskiy, V.; Kalhoff, J.; Nádherná, M.; Bresser, D.; Picard, L.; Fabre, F.; Rey, M.; Passerini, S. Beneficial influence of succinic anhydride as electrolyte additive on the self-discharge of $5 \mathrm{~V} \mathrm{LiNi}_{0.4} \mathrm{Mn}_{1.6} \mathrm{O}_{4}$ cathodes. J. Power Sources 2013, 236, 39-46. [CrossRef]

8. Bramnik, N.N.; Nikolowski, K.; Baehtz, C.; Bramnik, K.G.; Ehrenberg, H. Phase Transitions Occurring upon Lithium Insertion-Extraction of $\mathrm{LiCoPO}_{4}$. Chem. Mater. 2007, 19, 908-915. [CrossRef] 